\title{
Creating Connections to Land through Art: Allowing Curiosity to Take the Lead in Urban Spaces
}

\author{
Jeannette Heino, RECE
}

\begin{abstract}
Jeannette Heino is a registered early childhood educator and works at London Bridge Child Care Services Inc., in London, Ontario, as part of the centre's leadership team. Children's natural ability to feel joy, see wonder, and seek out curiosities first led Jeannette into this field. Early on, she discovered a love of writing and regularly spends time documenting her observations and interpretations of those observations. Over her 14-year career, her experiences have led her on a journey of studying what it means to "live in question," learning alongside both colleagues and children. She enjoys being part of a dynamic community where collaboration, reflection, questioning, and conversation continue to develop her thinking.

Email: jeannettevandermolen@gmail.com
\end{abstract}

When a child requested a visit to a colourful metal tree that she had seen on the way to the children's centre, we had no idea it would spark a journey of connection to the land through the art found in a bustling, urban, downtown setting. This article describes our journey as educators as we used questions to guide and push forward our practice with children. The questions provoked both children and educators to notice connections to the environment and how we might learn more about ourselves and the histories and stories of our surroundings. The purpose of this article is to consider how a series of metal tree art installations called our attention to the land we are on and the pedagogical possibilities that arose when we listened to questions proposed by both educators and the children in our care.

Key words: art; environment; urban nature
The Journal of Childhood Studies and Jeannette would like to thank Alex Berry for acting as a critical friend reviewer for this article.

\section{Walking with Questions}

London, Ontario, sits on the traditional lands of the Anishinaabe, Haudenosaunee, Huron-Wendt, Attawandaron, and Leni-Lunaape peoples, and is home to the Munsee-Delaware Nation, Oneida Nation of the Thames, and the Chippewas of the Thames First Nation. London is commonly known as the Forest City, as there are many gorgeous parks and conservation areas throughout the city limits, and many small pockets of green spaces nestled among the diverse neighbourhoods. Little Acorns Early Childhood Learning Centre, a part of London Bridge Child Care Services, is located on the main floor of an office building in a bustling urban centre that is replete with tall office buildings, busy traffic, a blending of businesses, and a rich art scene. As an educator and community member, I am passionate about the natural world and am often awestruck by artists' representations of that world. Being in an urban setting has given me an opportunity to experience the blending of natural, urban, and artistic spaces: London's art scene pervades the city as a whole, but is centralized in the downtown core. A child's fascination with the colourful metal trees they spotted on their way to their childcare centre prompted useducators and children - to go out and explore all that London had to offer. Bill Hodgson's Trees of the Carolinian Forest installation invited us into a place where nature met art in a new and exciting way and led us on a year-long walking investigation of the unique and eclectic neighbourhood that surrounds our centre. What started off as a quick walk down the street to look at the "pink tree" became so much more to the children and educators involved.

Walking with 16 children through the busy streets came with a few challenges, but we saw the importance it held for the children and worked through some logistics. After a few walks, we came together as educators and began to ask ourselves questions: How will we keep them safe and engaged? Where do we find the balance between safety 


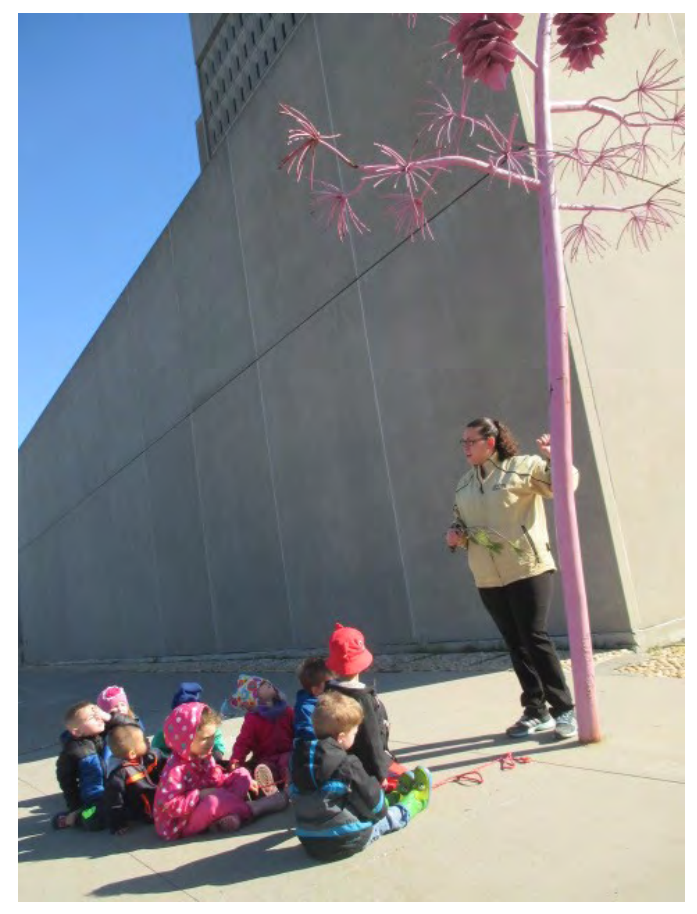

Figure 1: Our first meeting at the "Pink Tree."

and exploration in a place filled with a variety of people commuting from one building to another without really looking around? Can a downtown environment really hold their interest for an investigation? How can we collaborate alongside children to explore this space? These questions allowed us the opportunity to explore places that we passed by daily but were still quite unfamiliar to us. The hidden gems of the downtown core prompted us to look closer.

As we continued our exploration of the neighbourhood, it became apparent that while the children were drawn to the multiple artistic attractions of the downtown core, they were particularly drawn to the "colourful trees," as they affectionately called them. These colourful trees are placed in random spots downtown, and as the children grew more and more interested in finding them, our knowledge of the downtown core also grew. As we visited well-known places we had seen with our families, such as workplaces, shops, and parks, we also ran into people who would stop to talk with us, share stories, and lead us into new directions and discoveries. We began to discover seemingly hidden aspects of the downtown area as we searched for the trees: new and interesting art pieces tucked among the tall office buildings, almost waiting for the observant eye of a child to expose them. As the children discovered the many pieces of art the city had to offer, they also had the opportunity to have more conversations with each other. As we listened to their conversations about a particular piece of art, their curiosity sparked our own curiosity as educators and continued to push us forward. "Why did the artist pick these colours?" "How do real trees feel compared to the metal ones?" "Can children really create a strong connection to the land in an urban environment?" These questions allowed us to linger longer and move more slowly in a quickly moving environment. As the months progressed, the children's interest in the colourful trees did not fade, and their hunger to find new ones fuelled our inquiry. Our routes extended and changed to incorporate new streets even further away, and the children's varying abilities to walk further became correlated with their motivation to find the trees. As the children brought their excitement of our discoveries to their families through nighttime conv ersations and shared photos from our walks at pickup time, their families began to ask questions: "What are these colourful trees?" "I was surprised that she knew we were on Wellington Street!" "Did you walk by our work the other day?" "Have you guys visited the red tree near the Citi Plaza?" It seemed the more we spoke about our inquiry, the more the families opened up about their own experiences downtown. Families became partners in our inquiry, which only propelled us further along, giving us more to wonder about.

When the children found a new tree or a piece of art, they could not just passively sit back and observe it. They needed to experience it first-hand, feel its cool metal or rough exterior, and walk around it to see it from all angles. As the children grew increasingly attached to the trees, it was no

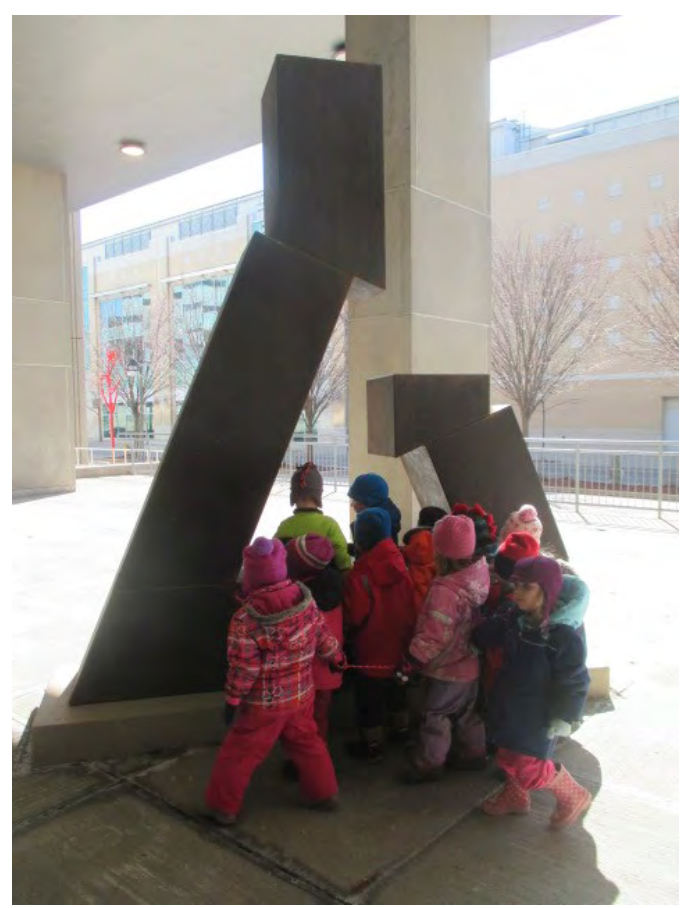

Figure 2: A large metal sculpture found tucked away at the Court House. 
longer enough to just look at them or touch them. They embraced the trees on a new level, one of relation and familiarity from our previous visits. They seemed to feel compelled to share more with each other. We began staying longer by the trees, which allowed us to become more attuned to our surroundings and what was happening beyond ourselves. The children began to attend to different aspects of the places in which they walked. Our routes throughout downtown became longer and more involved as the need to walk by our favourite trees compelled us to take new directions. It appeared that the colour of the trees was what originally attracted the children, but their relationship with the trees seemed to provoke them into looking again to make sure they were not missing any important detail that would help them know and understand

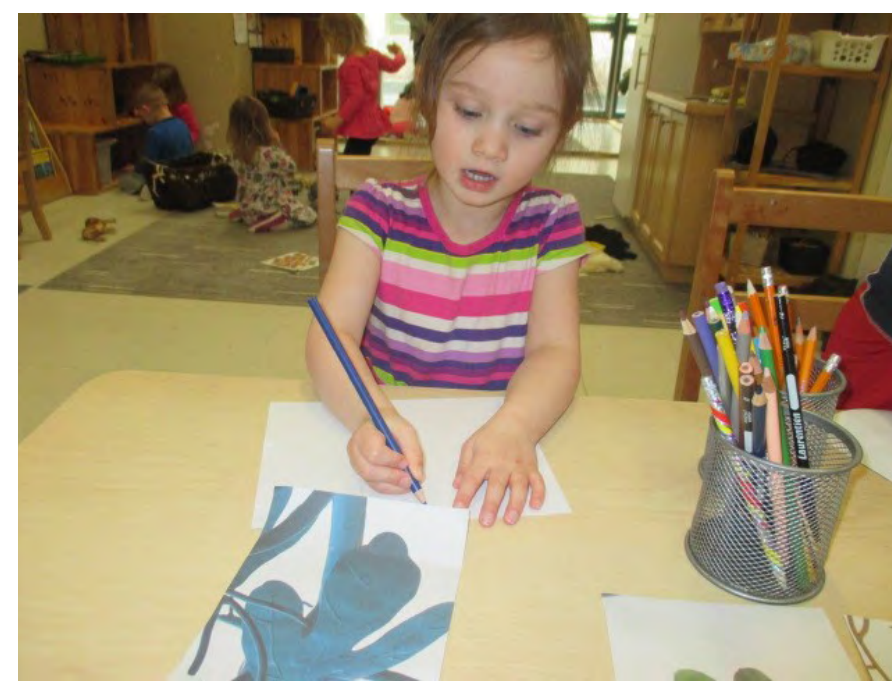

Figure 4: As we looked closer at the leaves of each tree, the children were inspired to draw.

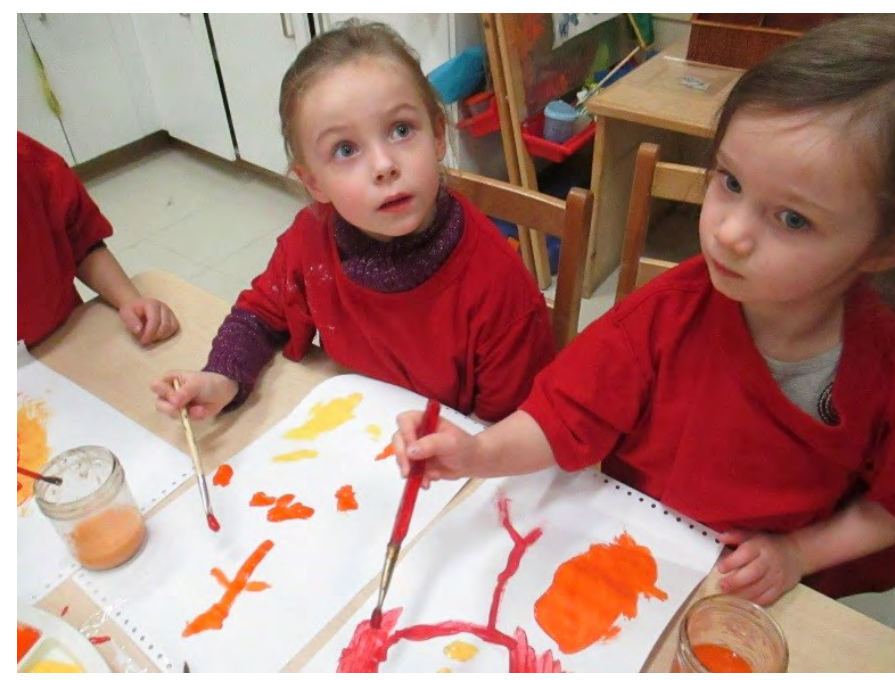

Figure 5: Art mediums were used to examine the trees and gain a different connection to them.

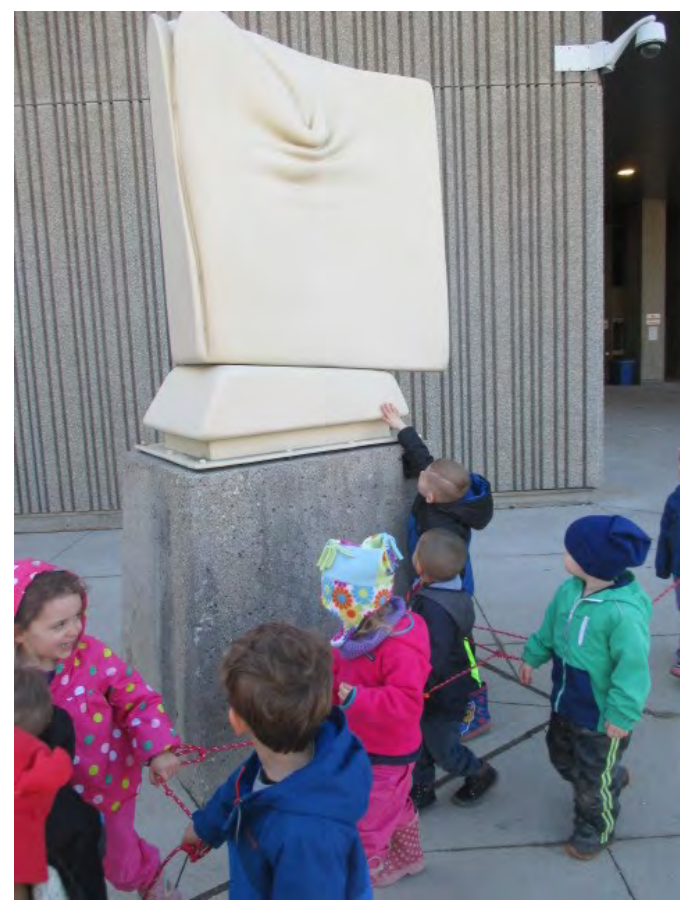

Figure 3: A new piece of art found along our walking route.

children's

passion for the

colourful trees found its way into our classroom: they wanted opportunities to draw their favourite trees and to create them using blocks or Legos, and soon our walks became intertwined with a material inquiry with clay in our centre's creative studio. We made photos of the trees available to aid the children as they worked with the clay. Echoing the trees' formation, the children brought the momentum of our outdoor walking inquiry indoors. While watching and participating alongside them as they explored the trees both indoors and outdoors, we saw an even deeper connection to the land they were walking on outside the centre.

The children investigated the trees' formal names, and soon the Pink Tree became the White Pine and the Green Tree became the Slippery Elm. Eventually the children were able to identify living trees based on their observations of the colourful ones. The colourful trees began to show more of their history and the reason they were there slowly became clear. The trees that the artist chose to represent are indigenous to this area and have meaning to the land. Black Oak, White Oak, Aspen, Sassafras, White Pine, Elm, and Birch took the place of the children's pet names. The Blue Tree in front of the building where the London 
Knights play also underwent a name change. A comment about it made by a child demonstrated the subtle shift in their thinking: "It's the Sassafras tree in front of Bud Gardens. That's where they play hockey." It seemed that the children's need for more accuracy and details about their surroundings began to apply to more than just the trees.

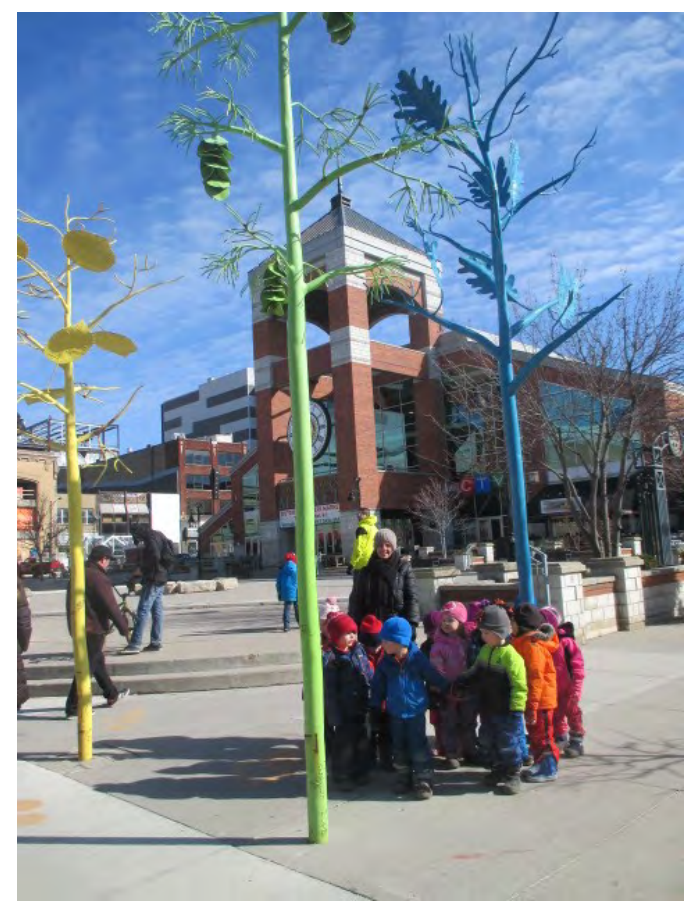

Figure 6: A group of trees we found at the market.

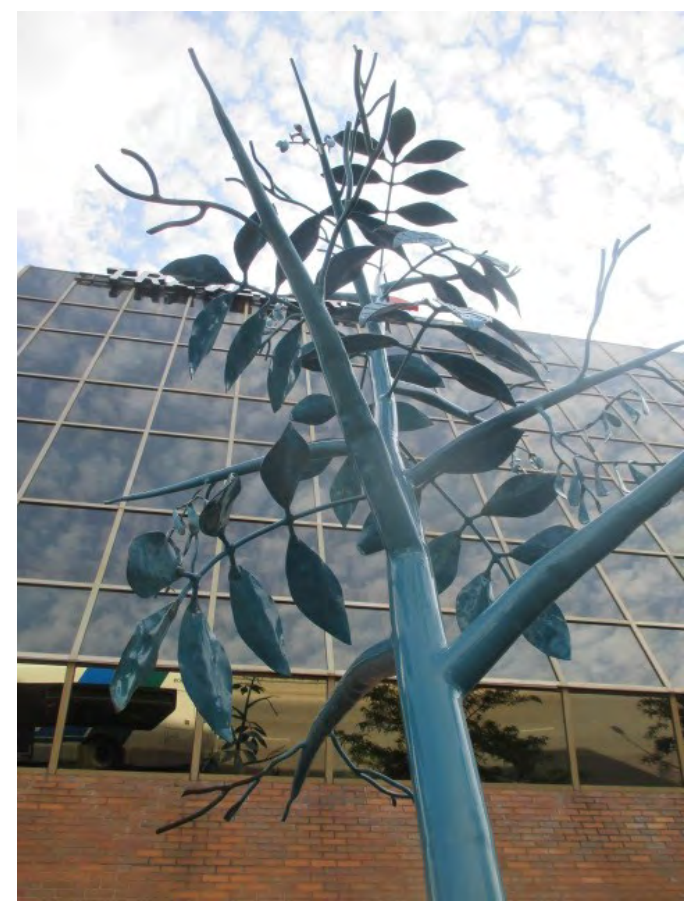

Figure 7: An invitation to look at the world from a new perspective. They realized that each building too had a name, a reason for being in its spot. The children experienced a collective bond with the trees as we walked throughout downtown, seeing the trees as old familiar friends and discovering new and interesting ones to add to our list.

Throughout our inquiry, we had many different educators-supply, support, and full-time-join us on our adventures downtown. As such, we had a wonderful opportunity to discuss each other's perspectives during regular meetings about our walks where we could ask each other questions to understand more about what we were seeing. Having such a variety of educators along for the inquiry increased the urgency to make time for these meetings as soon as possible. Collaborating with families also became essential for the flow of our inquiry. As our time with the children neared its end, and they prepared to move on to elementary school, we reached a point where we were unsure of how to proceed. We wanted to hear new perspectives from more educators from the broader London Bridge umbrella. We decided to invite educators and members of the community to share their views and questions about our inquiry. After this exchange we were able to move forward with a new outlook on our inquiry, which showed us the immense value of returning to our own questions, working alongside each other as educators, and dissecting children's observations and experiences in a new environment.

\section{Staying with questions}

Working in a centre located in a bustling downtown core can be somewhat daunting, given the noise, traffic, and multitudes of people moving from one place to another, always hurrying. Though the children are very familiar with this place, taking them into this urban environment and giving them an opportunity to explore its various aspects allows us to see what unexpected attributes this cityscape has to offer. Following the children's lead, and our own curiosity, we go off to ask and answer our own questions within this area. The children's fascination with an idea and a conflict of understanding in our encounters with natural and metal trees provoked us to notice a juxtaposition: organic trees that are stoic in nature, swaying in the wind and a symbiotic part of their environment, contrast with the colourful metal trees, which are unmoving, solid, and standing stark against the backdrop of the buildings. This makes me wonder: What are the children's understanding of trees and how did this art installation challenge them? Are these metal, seemingly unmoving trees also a symbiotic part of the urban environment? Is this art piece about bringing our attention to our changing natural/cultural 
environments and how they intermingle with each other? How does this affect my view on the changing spaces that we bring children into? How are our histories implicated here? Art allows us the opportunity to ask these questions. When we began our walks, I wanted to make sure the children had the opportunity to see the nature that surrounds our downtown location. I did not anticipate that the children would allow me to see the urban nature in plain sight.

The artist's work offer us questions about the metal tree sculptures, even among the adults who notice them as they pass by. What do they represent? How do they affect us? What is their meaning? What are the ideas behind this installation? And all too often it seems adults who walk past them are too busy to consider these questions. Walking with the children, we became ripe to answer questions and ponder our own curiosities alongside the children's. When we began our inquiry, the adults we encountered had mixed reactions to the trees. The trees were often described on local blog posts as a "waste of taxpayers' dollars." Questions bubbled about why real trees were not used instead. Misunderstanding and differing perspectives challenged me to think more. How would these differing perspectives affect our inquiry? What was our responsibility to others while we explored shared spaces that people used to get from place to place? Looking at these tall giants from the perspectives of the children allowed our classroom educators and parents the opportunity to see the kindness of strangers and the beauty of art and experience a feeling of community. It also gave us a sense of visibility within the community. When did it become more than just noticing the art intermingled with the buildings and more about understanding the tensions and contradictions that the art provokes? How can we bring this curiosity, this call to notice, to others around us as we walk between places?

\section{A change in perception}

When we began our walking inquiry, the children initially noticed more obvious aspects of their surroundings: the tallness of the buildings, their parents' workplaces, the colours and shapes. As we continued our journey, those superficial observances became more in-depth. We noticed how the clouds subtly moved behind the buildings, making the buildings appear to almost sway alongside them. Months into our inquiry we finally noticed the names of the natural trees and sculptures written in cursive at the base of the installations. As we craned our necks way back, our observations gave way to conversations between educators and children about movement and about memories of watching clouds pass by with our families. Passersby and other educators became a part of the conversations and gave us a way to see something from even more new perspectives.

While we walked down the brick sidewalks, the stark colours of red, blue, yellow, pink, and green in the trees stood out for us among the grey stone and glass buildings. Adults would generally walk by the colours without so much as a glance, but the children's excitement seemed to pull them in. Strangers became collaborators in our conversations as the children explained to them what the trees were. Our conversations expanded to include others' perspectives, stories, and experiences with downtown London. The children's voices opened up more communication for those simply heading from one place

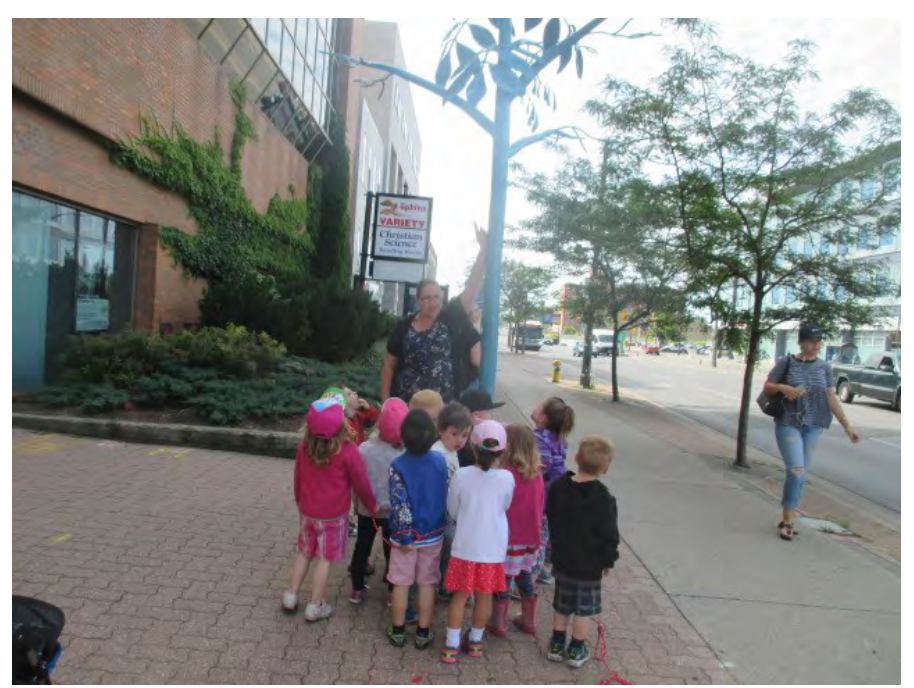

Figure 8: As we ventured further and further from our centre, we found different trees to examine. A child brought this tree to our attention and wanted to show it to others in the class. 
to another and broadened our own views on what we were seeing. Just as the art seemed to have its own place within the community, so too the children were carving out a place of their own. The children became more visible in the fabric of the downtown community as they assisted others in seeing through the lens of a child again. They became part of a story that was being told in the moment.

\section{Walking among tensions}

In the past, walks with the children in our class seemed to be more about a destination. Getting the children from one place to another mirrored my experiences downtown as a community member. As an adult, I would walk to get somewhere, whether it was from my car to my workplace, to the corner store, or to a neighbour's house. It had become an automatic process. However, walking with the children during this inquiry helped to remind me to look through a lens of curiosity and openness. When I, as an educator, began to stop more and wonder alongside the children, it gave me an opportunity to see things, events, and people a little closer and a little more in-depth, to see the detail, and to slow down.

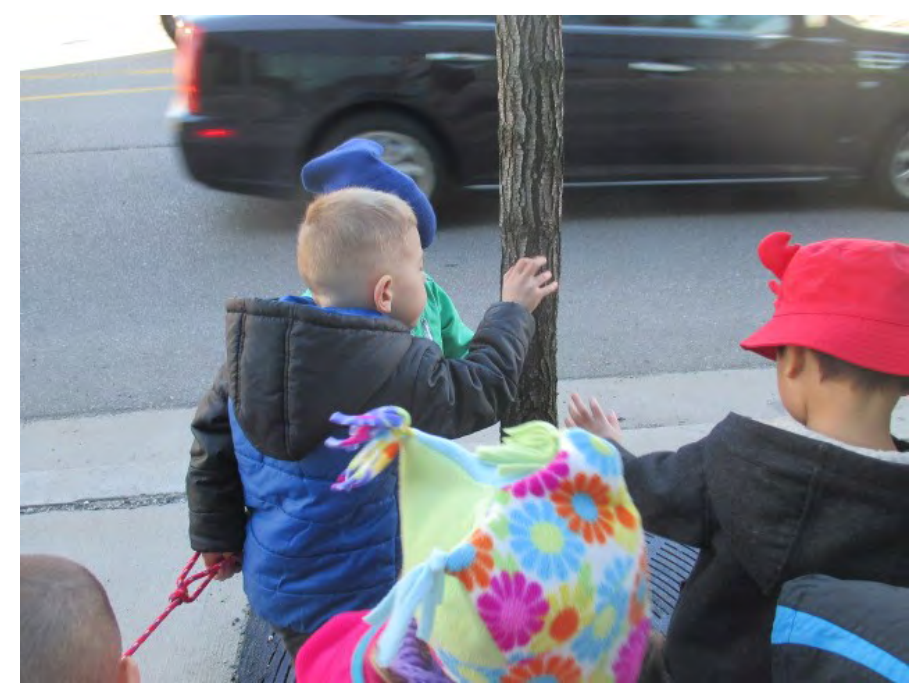

Figure 9: The idea of how the trees felt came into play and the children went on a walk exploring the trunks of different live trees along our routes. This also led to a discovery of the names of the metal tree sculptures written in cursive at the bottom.

I have now noticed a difference in my personal walks with my own family. We stop a bit more, creating familiar spots that we reexamine again and again. Walking in this way has helped me to establish a stronger connection to the land amid its tension, to the place I call home. When I am outside, regardless of where I am, I have always felt a strong connection to the earth, to the stories that happened before my time. I enjoy noticing plants that I have never seen before and the excitement of spotting wildlife hidden in the underbrush at the park. Walking downtown among the tall buildings, tensions arise as I recognize that this place has stories from before that are harder to find within the concrete structures that surround me. How do I arrive on this land? Where does my story connect with that of the land that I walk on?

My own story is one of personal discovery. I am proud to be a mix of several different nationalities. I have roots in Europe and Africa and have Indigenous ancestry. My family is still working to retrace the specific areas of land that we belong to. As I walk on the land of the Anishinaabe, Haudenosaunee, Huron-Wendt, Attawandaron, and LeniLunaape Nations, I feel a mixture of emotions, including tension. I feel a strong connection to the land through my Indigenous roots, and a sense of peace and calm as I use all of my senses to explore. However, with my European 


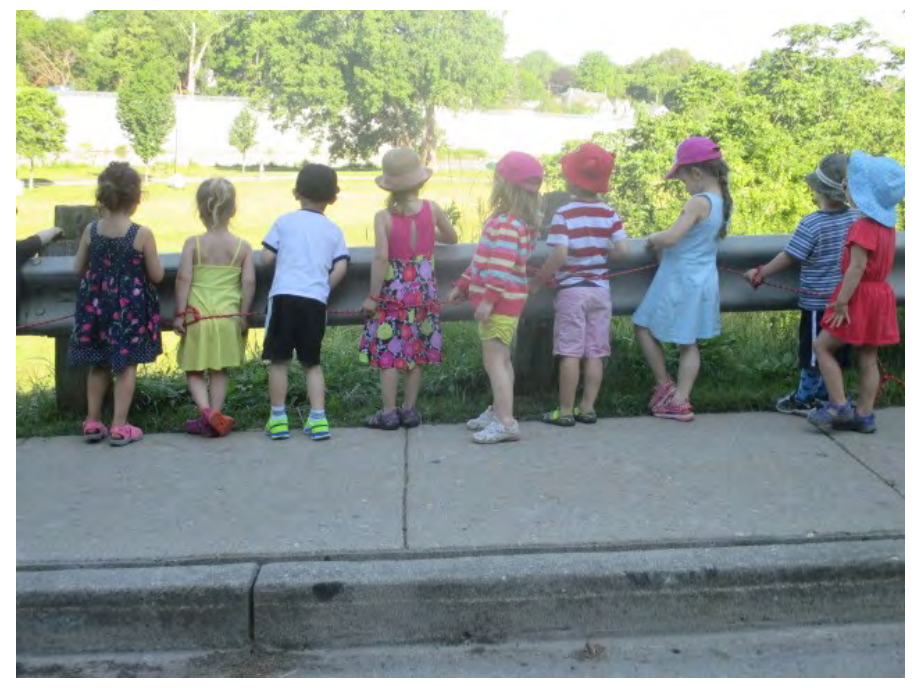

Figure 10: Exploring a natural space where the Thames River (Askunesippi-Antlered River) runs through.

ancestry, I feel conflicted because I see how colonization has affected this neighbourhood and the people whose land I walk on. I am still learning about who I am and who my ancestors are. Our stories-my stories-have been lost over the decades. As a member of an entire generation without family origin stories, I am struggling to find out who and where I come from, a wondering about my nation and history that fuels my curiosities on our walks. The lands that we walk on may have belonged to my ancestors, and knowing this raises questions for me as I walk here. How can I incorporate my own personal journey of self-discovery with the children I teach? Walking by the Thames River that runs through our city, my question becomes "What was this river's story before colonization?" Talking about these histories alongside children provides them with the opportunity to see there is more to their neighbourhood than what they see and propels me to continue looking deeper into my own histories.

I am still curious: What is it about the colourful trees that prompted the children to learn more and sustained their attention for such a long period? Why were they entranced? These questions motivate me to continue to slow down and be a co-learner alongside the children. I am able to learn even more about myself through our discoveries with the trees. I am surprised that I can learn so much about the natural environment and our city's indigenous plants through a metal tree installation. I remember becoming more excited as the children pointed me to different aspects of a space that I had walked so many times before. Even now, with the inquiry finished, I have taken my wonder and curiosity and applied them to new environments that I visit. This drives me to find those aspects of the land that I can connect to, ground myself in these spaces, and ask deeper questions about the land that I walk on. I think about not only the last 50 years, but further back-100, 200, 500 years-and how the stories of those years impact us now. I understand and see the importance of the stories of the land that I walk and take this with me as I continue on my personal and professional journey.

\section{Conclusion}

During our walking inquiry in a neighbourhood I have worked in for many years but never explored, I found myself drawn to many more aspects of this place than I expected. The children's unanswered questions, the artistic structures, and the urban and natural materials shared complex histories with me as I walked by them. Paying attention to the land that I walk upon, amid its contradictions, has become both a necessity and a responsibility as I walk alongside the children in my care. While speaking about this urban environment, it is necessary to also think about how the colonization of this area affects the children and people living on it, and how these spaces 
differ from the visions Indigenous Peoples had, and continue to have, for this place. The metal tree sculptures bring attention to plants that are indigenous to this area. I wonder how Indigenous histories are represented in this place, and what responsibilities I have as an educator in honouring this land and the original inhabitants whose ancestors continue to care for it. What might walking with land and attending to the art found within it offer us in times of reconciliation? The children's curiosity, coupled with my own, gave life and importance to our relationships with the land we stepped on. With the help of the Trees of the Carolinian Forest, we were able to pay attention to the contradictory presences of the urban and natural worlds and how they are entangled with each other. By slowing down our thoughts and movements as we explored these spaces, we were able to be present, to notice this intermingling and consider what it might mean to walk here. Our inquiry allowed us to not only walk with a destination in mind, but also to walk without one, to see further, to question deeper, and to learn more.

\section{Acknowledgment}

I would like to extend a special thank-you to Bill Hodgson (1956-2017) for giving us sculptures that made us think, brought us together and created a stronger sense of community. 